\title{
Phase I study of third-line palliative chemotherapy with low dose paclitaxel for pancreatic cancer
}

\author{
HIDEHIRO TAJIMA, MITSUYOSHI OKAZAKI, TAKAHISA YAMAGUCHI, YOSHINAO OHBATAKE, \\ KOICHI OKAMOTO, SHINICHI NAKANUMA, SHIRO TERAI, SEISHO SAKAI, JUN KINOSHITA, \\ ISAMU MAKINO, KEISHI NAKAMURA, HIRONORI HAYASHI, KATSUNOBU OYAMA, MASAFUMI INOKUCHI, \\ TOMOHARU MIYASHITA, HIROYUKI TAKAMURA, ITASU NINOMIYA, SACHIO FUSHIDA and TETSUO OHTA
}

Department of Gastroenterological Surgery, Division of Cancer Medicine, Graduate School of Medical Science, Kanazawa University, Kanazawa 920-8641, Japan

Received November 18, 2017; Accepted February 16, 2018

DOI: $10.3892 / \mathrm{mco} .2018 .1579$

\begin{abstract}
The prognosis of patients with unresectable or recurrent pancreatic cancers is very poor. Prior to development of nab-paclitaxel (PTX) plus gemcitabine (GEM) therapy and FOLFIRINOX therapy, there was no recommended third-line chemotherapy after 5-fluorouracil (5-FU) and GEM-based regimens. The present study conducted a Phase I clinical trial of weekly low-dose PTX as a third-line palliative chemotherapy for patients with pancreatic cancer. PTX was administered on days $1,8,15$, and 22 of each cycle, repeated twice as follows: Level 1, $40 \mathrm{mg} / \mathrm{m}^{2}(\mathrm{n}=6)$; Level 2, $50 \mathrm{mg} / \mathrm{m}^{2}(\mathrm{n}=4)$. During the two cycles, three patients developed Grade 3 neutropenia in level 2; thus, the recommended dose was defined as $40 \mathrm{mg} / \mathrm{m}^{2}$. The disease control rate was $40.0 \%$ (stable disease, $n=4$ ). Median time to treatment failure of the four patients with stable disease was 5.5 months. In conclusion, palliative chemotherapy with low-dose PTX after failure of GEM and 5-FU is well tolerated and safe for unresectable or recurrent pancreatic cancer patients. The unique ID issues by UMIN: 000008148 .
\end{abstract}

\section{Introduction}

Pancreatic cancer is a major cause of cancer-related mortality worldwide, the 5-year survival rate being $2-6 \%(1,2)$. Indeed, even in patients who undergo resection, the 5-year survival rate is poor at between 7 and $24 \%$, whereas the median survival time is about 1 year in the majority of series (3). Certainly, the prognosis of unresectable or recurrent patients is even worse. Recently, the advent of nab-paclitaxel (nab-PTX) plus gemcitabine (GEM) therapy and 5-FU, leucovorin, irinotecan

Correspondence to: $\mathrm{Dr}$ Hidehiro Tajima, Department of Gastroenterological Surgery, Division of Cancer Medicine, Graduate School of Medical Science, Kanazawa University, 13-1 Takaramaci, Kanazawa 920-8641, Japan

E-mail: hidetaji@staff.kanazawa-u.ac.jp

Key words: pancreatic cancer, low dose, paclitaxel, palliative chemotherapy, third line chemotherapy and oxaliplatin (FOLFIRINOX) therapy offered a ray of hope for treatment of unresectable pancreatic cancer $(4,5)$. Prior to appearance of these powerful regimens, no third-line chemotherapy was recommended after 5-FU and GEM-based regimens. In addition, such a powerful treatment can no longer be used gradually in the terminal stage. Palliative chemotherapy superior to best supportive care (BSC) is required at such time.

Paclitaxel (PTX) is an anticancer agent used for various malignant diseases previously (6) that stabilizes polymerized microtubules and enhances microtubule assembly, which arrests the cell cycle in G0/G1 and G2/M phases, and leads to cell death $(7,8)$. Low-dose PTX ameliorates tissue fibrosis by inhibiting the activity of transforming growth factor (TGF)- $\beta /$ Smad activity $(9,10)$. Therefore, we reasoned that paclitaxel might be useful for treating patients with pancreatic and biliary tract cancer (BTC) associated with tissue fibrosis.

We found that low-dose PTX inhibits the epithelial mesenchymal transition (EMT) of cholangiocarcinoma cells treated with TGF- $\beta$ (11). Furthermore, we studied the responses of patients with BTC treated with low-dose PTX as palliative chemotherapy following GEM and S-1 (oral prodrug of 5-FU) $(12,13)$. Thereafter, we planned a Phase I clinical trial to determine the optimal dose of weekly low-dose PTX therapy as third-line palliative chemotherapy for patients with pancreatic cancers after failure of S-1 and GEM.

\section{Patients and methods}

Patient selection. Patients with unresectable or recurrent pancreatic cancers after excision who had been treated with GEM and S-1 were eligible for this study. Other inclusion criteria were as follows: age 20-80 years, Eastern Cooperative Oncology Group (ECOG) performance status $\leq 1$ (ambulatory and capable of self-care), adequate renal function (normal serum creatinine and blood urea nitrogen concentrations), adequate liver function (total bilirubin, <2.5-times the upper normal limit [UNL] or < triple the UNL after biliary drainage in patients with jaundice and serum transaminase [GOT, GPT] concentrations <2.5-times the UNL or < triple the UNL after biliary drainage in patients with jaundice), adequate 
bone marrow reserve (white blood cell count, 4.0-12.0x109/1; neutrophil count, $>2.0 \times 109 / 1$; platelet count, $>100 \times 109 / 1$; and hemoglobin $>95 \mathrm{~g} / \mathrm{l})$, and adequate pulmonary function $\left(\mathrm{PaO}_{2}\right.$, $>70 \mathrm{mmHg}$ ). Patients with a history of treatment for pancreatic cancer must have discontinued such treatment (tumor resection, chemotherapy, immunotherapy, or radiotherapy) $\geq 2$ weeks before enrolment.

Exclusion criteria were as follows: pulmonary fibrosis or interstitial pneumonia, marked pleural or pericardial effusion, marked peripheral edema, severe heart disease, difficult-to-control diabetes mellitus, active infection, pregnancy or lactation, women of childbearing age not using effective contraception, severe drug hypersensitivity, severe neurological impairment, severe mental disorder, active concomitant malignancy, previous history of PTX administration, complications of another malignancy, and other serious medical conditions.

Written informed consent was obtained from each patient before enrolment, and the Institutional Review Board of Kanazawa University Hospital approved this study (UMIN ID: 000008148).

Study design. This was an open-label, single-center, nonrandomized, dose-escalation Phase I study. Laboratory tests to assess eligibility were completed within 7 days before commencing treatment. PTX was administered as a 60-min intravenous infusion on Days 1, 8, 15, and 22 of each cycle. A second cycle was then administered at the specified higher dose level beginning on Day 28. The doses of PTX were planned as follows: Level 1, $40 \mathrm{mg} / \mathrm{m}^{2}$; Level $2,50 \mathrm{mg} / \mathrm{m}^{2}$. If the treatment was found to be effective after two cycles, it was continued weekly or biweekly for as long as possible.

Definition of dose-limiting toxicity (DLT) and maximum tolerated dose (MTD). DLT was determined during each treatment cycle and defined according to the National Cancer Institute's Common Toxicity Criteria scale (version 4.0) (http://ctep. cancer.gov/protocolDevelopment/electronic_applications/ctc.htm \#ctc_40) as one or more of the effects attributable to the study drug as follows: i) Grade 3/4 neutropenia complicated by fever; ii) Grade 4 neutropenia $>4$ days; iii) Grade 4 thrombocytopenia; iv) any other Grade 3/4 nonhematologic toxicity except anorexia, nausea, and vomiting in the absence of an appropriate antiemetic; and v) delay of recovery from treatment-related toxicity for more than 2 weeks. At least three patients received each dose level. If DLT was observed after the first cycle in more than two patients, treatment at that dose was discontinued. If DLT was observed after the first cycle in one patient, three additional patients were administered that dose level. If only one of six patients experienced DLT, dose escalation was continued. The MTD of the combination was defined as the dose that produced DLT in more than two of six patients or in the initial three patients. The recommended dose (RD) was defined as the dose that was one level below the MTD. Because the aim was palliation, if Level 2 was less than the MTD, no further dose escalation was implemented and Level 2 became the RD.

Assessment of efficacy. Tumor responses were evaluated according to the Response Evaluation Criteria in Solid
Tumors (14). Complete response (CR) was defined as disappearance of clinical evidence of the tumor. Partial response (PR) was defined as a $\geq 30 \%$ reduction in the sum of the products of two orthogonal diameters of all measurable lesions compared with baseline values with no evidence of new lesions. Stable disease (SD) was defined as $<30 \%$ reduction or $<20 \%$ increase in the sum of the products of two orthogonal diameters of all measurable lesions compared with baseline values with no evidence of new lesions. Progressive disease (PD) was defined as $\geq 20 \%$ increase in the sum of the products of two orthogonal diameters of all measurable lesions compared with baseline values, appearance of a new lesion, or deterioration in clinical status consistent with disease progression. Patients were evaluated for objective evidence of response after two cycles of chemotherapy. Additionally, concentrations of the tumor markers carcinoembryonic antigen (CEA), cancer antigen (CA)19-9 and Duke pancreatic monoclonal antigen type 2 (DUPAN-2) were measured before and after two treatment cycles.

Statistical analysis. The median survival time (MST) and OS were calculated from the start of treatment until death and were determined using the Kaplan-Meier method. The significance of differences CEA and CA19-9 concentrations were evaluated using Student's paired t-test after logarithmic transformation of the values and $\mathrm{p}<0.05$ was considered to indicate statistical significance. A SPSS statistical package (version 19; SPSS, Chicago, IL, USA) was used to perform the analyses.

\section{Results}

From May 2012 to January 2014, 10 patients (three men and seven women) diagnosed as having recurrent or unresectable pancreatic cancers after failure of GEM and oral S-1 were enrolled in this study. The patients' characteristics and the effects of treatment are listed in Table I. Treatment was administered at Level $1\left(40 \mathrm{mg} / \mathrm{m}^{2}\right)$ to six patients and Level 2 $\left(50 \mathrm{mg} / \mathrm{m}^{2}\right)$ to four patients. The following responses were documented: PR, none of 10 patients $(0.0 \%)$; SD, four $(40.0 \%)$; and $\mathrm{PD}$, six $(60.0 \%)$; thus, the disease control rate (PR+SD) was $40.0 \%$. During the two courses of therapy, Grade 1 or 2 adverse events occurred in all patients, dose-limiting adverse events (Grade 3 or 4 ) occurring in three patients receiving Level 2. However, eight patients completed two courses of treatment, the remaining two discontinuing treatment because of disease progression. Adverse events were as follows: epilation $(100.0 \%)$, anemia $(100.0 \%)$, neutropenia (Grade 1 or 2: $20.0 \%$, Grade 3 or $4: 30.0 \%$ ), thrombocytopenia $(10.0 \%)$, general malaise $(40.0 \%)$, and liver dysfunction (20.0\%). No significant neuropathy or anorexia were observed during the two treatment cycles (Table II). Dose-limiting adverse events (Grade 3 or 4 ) occurred in three of four patients receiving Level 2 (neutropenia). Thus, dose escalation was aborted at Level 2 and Level 1 was defined as MTD and RD.

Before treatment, CEA concentrations were high $(>5 \mathrm{ng} / \mathrm{ml})$ in six of 10 patients, CA-19-9 concentrations $(>37 \mathrm{U} / \mathrm{ml})$ in nine of 10 patients, and DUPAN-2 concentrations $(>150 \mathrm{U} / \mathrm{ml})$ in seven of 10 patients. CEA and DUPAN-2 concentrations each decreased in only one patient, whereas CA19-9 concentrations 
Table I. Patient's characteristics and treatment effects.

\begin{tabular}{|c|c|c|c|c|c|c|c|}
\hline No. & $\begin{array}{l}\text { Age, } \\
\text { years }\end{array}$ & Sex & $\begin{array}{l}\text { Tumor } \\
\text { location }\end{array}$ & $\begin{array}{c}\text { Dose } \\
\left(\mathrm{mg} / \mathrm{m}^{2}\right)\end{array}$ & Operation & $\begin{array}{c}\text { Treatment } \\
\text { effect }\end{array}$ & $\begin{array}{c}\text { TTF } \\
\text { (months) }\end{array}$ \\
\hline 1 & 65 & $\mathrm{~F}$ & BT & 40 & + & PD & 0 \\
\hline 2 & 61 & $\mathrm{~F}$ & BT & 40 & + & PD & 0 \\
\hline 3 & 65 & $\mathrm{~F}$ & BT & 40 & - & PD & 0 \\
\hline 4 & 62 & $\mathrm{~F}$ & $\mathrm{H}$ & 40 & + & SD & 9 \\
\hline 5 & 65 & $\mathrm{~F}$ & BT & 40 & - & PD & 0 \\
\hline 6 & 74 & $\mathrm{~F}$ & BT & 40 & + & SD & 4 \\
\hline 7 & 69 & $\mathrm{M}$ & BT & 50 & - & PD & 0 \\
\hline 8 & 45 & $\mathrm{M}$ & BT & 50 & - & PD & 0 \\
\hline 9 & 62 & $\mathrm{~F}$ & BT & 50 & + & SD & 4 \\
\hline 10 & 71 & $\mathrm{M}$ & $\mathrm{H}$ & 50 & + & SD & 5 \\
\hline
\end{tabular}

F, female; M, male; BT, body and tail; $\mathrm{H}$, head; $\mathrm{PD}$, progressive disease; $\mathrm{SD}$, stable disease; TTF, time to treatment failure.

Table II. Adverse events.

\begin{tabular}{lcc}
\hline & Grade 1,2 & Grade 3,4 \\
\hline Neutropenia & $2(20.0 \%)$ & $3(30.0 \%)$ \\
Anemia & $10(100 \%)$ & 0 \\
Thrombocytopenia & $1(10.0 \%)$ & 0 \\
Anorexia & 0 & 0 \\
General malaise & $4(40.0 \%)$ & 0 \\
Liver dysfunction & $3(30.0 \%)$ & 0 \\
Neuropathy & 0 & 0 \\
Epilation & $10(100 \%)$ & - \\
\hline
\end{tabular}

decreased in four patients; however, the decreases in these tumor marker concentration were not significant (data not shown).

OS from the start of treatment until death and MST were 0.77 months (range: 0.45-1.09) and 0.47 months, respectively (Fig. 1).

\section{Discussion}

Before development of nab-PTX+GEM and FOLFIRINOX therapies, the key drugs for treating pancreatic cancer were 5-FU and GEM. 5-FU was the major drug used to treat hepatobiliary-pancreatic cancers; however, Phase II studies of combinations based primarily on 5-FU regimens show little or no benefit in survival or quality of life $(11,12)$. In a Phase III GEST trial, S-1, an oral prodrug of 5-FU that is widely used in Japan, achieved favorable responses and was not inferior to GEM for increasing the OS of patients with unresectable pancreatic cancer (15). Moreover, the JASPAC 01 trial found that S-1 prior to GEM is effective adjuvant chemotherapy for resected pancreatic cancer (16). However, there was no recommended third-line chemotherapy following GEM and 5-FU for treating patients with pancreatic cancer.

PTX is isolated from the Western Yew, Taxus brevifolia (4). Similar to vinca alkaloids, it binds microtubules. However, whereas vinca alkaloids promote microtubule dissociation and disruption of the mitotic spindle, PTX promotes micro-

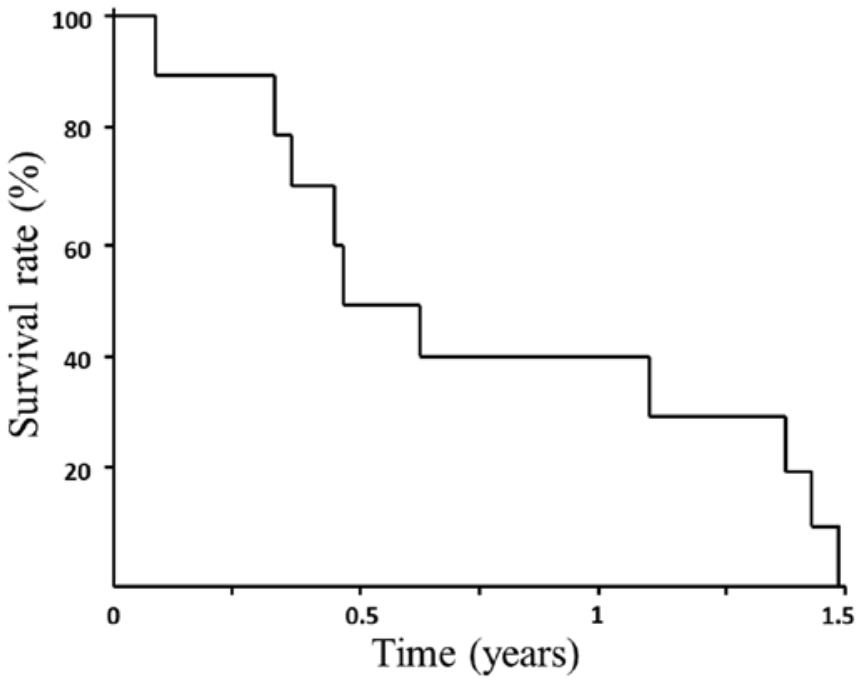

Figure 1. Overall survival curve for 10 patients with pancreatic cancer after induction of third-line chemotherapy with low-dose weekly paclitaxel. The mean survival time from the start of treatment until death and median survival time were 0.77 months (range, $0.45-1.09$ ) and 0.47 months, respectively.

tubule formation and stabilization. Both retrospective studies and Phase I and II studies of PTX and docetaxel (taxanes) on treating patients with pancreatic cancer (17-20) have reported disease control rates of $33-57 \%$ when this regimen is used as first or second line chemotherapy.

PTX is currently receiving attention for its effects on pathologies other than cancers. For example, PTX is incorporated into drug-eluting stents placed in coronary arteries (21). Moreover, PTX ameliorates fibrosis in hepatic stellate cells and renal fibrosis through inhibition of TGF- $\beta / \mathrm{Smad}$ activity $(9,10)$. Further, paclitaxel inhibits paracrine TGF- $\beta 1$ signaling between gallbladder epithelial cells and myofibroblasts (22).

PTX decreases interstitial fluid pressure and improves oxygenation of breast cancer tissues of patients treated with neoadjuvant chemotherapy (23). Thus, taxanes may be effective for treating fibrous hypoxic tumors such as pancreatic cancer. For example, nab-PTX + GEM therapy increases the treatment options for patients with pancreatic cancer (24); this therapy disrupts stroma in these patients (25).

Taxanes are used to treat patients with GEM-refractory pancreatic cancer $(26,27)$. Anticancer drugs, irradiation, hypoxia, malnutrition, and heat induce EMT of cancer cells and activation of fibroblasts, which is involved in the invasive potential of cancer cells and cancer associated fibroblasts (28). The inhibitory effect of PTX on TGF- $\beta /$ Smad activity contributes to suppression of the EMT (9).

We have previously reported that PTX is more effective, as assessed by time to treatment failure, than GEM and S-1 for treating patients with unresectable gallbladder cancer (10). Thus, a Phase I study of low-dose PTX, which has fewer adverse effects, is warranted for palliative chemotherapy in patients with BTCs (13). Of note, PTX is an established palliative chemotherapy agent for treating patients with breast cancer (29). In the present Phase I study, we demonstrated the efficacy and safety of weekly low-dose PTX as third-line chemotherapy for patients with pancreatic cancer. Moreover, 
$40 \mathrm{mg} / \mathrm{m}^{2}$ of PTX was the MTD after 8 weeks of weekly administration, and thus defined as RD. A past study to determine the appropriate dose of PTX in patients with BTCs was terminated at $50 \mathrm{mg} / \mathrm{m}^{2}$ (13). Moreover, low dose PTX as third line palliative chemotherapy was found to be more effective in patients with BTC than in those with pancreatic cancer. These results suggest that the general condition of patients with pancreatic cancer may be poorer than that of patients with BTC considering third line chemotherapy. However, this study is just a phase I; comparison with placebo or BSC group is necessary in phase II study in the future.

In conclusion, after failure of therapy with GEM and 5-FU, palliative chemotherapy with low-dose PTX is well-tolerated and safe in patients with unresectable or recurrent pancreatic cancer, the RD being $40 \mathrm{mg} / \mathrm{m}^{2}$. In the future, it is considered that Phase II trial and Phase III trial compared with BSC are necessary.

\section{Acknowledgements}

Not applicable.

\section{Funding}

No funding was received.

\section{Availability of data and materials}

The datasets used and/or analyzed during the current study are available from the corresponding author on reasonable request.

\section{Authors' contributions}

The authors, MO, TY, YO, KOk, SN, ST, SS, JK and IM, conducted chemotherapy on patients, KN, HH, KOy, MI and TM contributed to the clinical data analysis, HTaj, HTak, IN and SF contributed the clinical trial operation. TO conducted the clinical study. All authors read and approved the final manuscript.

\section{Ethics approval and consent to participate}

Written informed consent was obtained from each patient prior to enrolment, and the present study was approved by the Institutional Review Board of Kanazawa University Hospital (Takaramaci, Japan).

\section{Competing interests}

The authors declare that they have no competing interests

\section{References}

1. Von Hoff DD, Ervin T, Arena FP, Chiorean EG, Infante J, Moore M, Seay T, Tjulandin SA, Ma WW, Saleh MN, et al: Increased survival in pancreatic cancer with nab-paclitaxel plus gemcitabine. N Engl J Med 369: 1691-1703, 2013.

2. Suker M, Beumer BR, Sadot E, Marthey L, Faris JE, Mellon EA, El-Rayes BF, Wang-Gillam A, Lacy J, Hosein PJ, et al: FOLFIRINOX for locally advanced pancreatic cancer: A systematic review and patient-level meta-analysis. Lancet Oncol 17: 801-810, 2016.
3. Evans DB, Abbruzzese JL and Willett CG: Cancer of the pancreas. In: Cancer: Principles and Practice of Oncology. 6th edition. DeVita VT Jr, Hellman S and Rosenberg SA (eds). Lippincott Williams and Wilkins, Philadelphia, pp1126-1161, 2001.

4. Von Hoff DD, Ramanathan RK, Borad MJ, Laheru DA, Smith LS, Wood TE, Korn RL, Desai N, Trieu V, Iglesias JL, et al: Gemcitabine plus nab-paclitaxel is an active regimen in patients with advanced pancreatic cancer: A phase I/II trial. J Clin Oncol 29: 4548-4554, 2011

5. Conroy T, Desseigne F, Ychou M, Bouché O, Guimbaud R, Bécouarn Y, Adenis A, Raoul JL, Gourgou-Bourgade S, de la Fouchardière C, et al; Groupe Tumeurs Digestives of Unicancer; PRODIGE Intergroup: FOLFIRINOX versus gemcitabine for metastatic pancreatic cancer. N Engl J Med 364: 1817-1825, 2011.

6. Gelmon K: The taxoids: Paclitaxel and docetaxel. Lancet 344: 1267-1272, 1994.

7. Donaldson KL, Goolsby GL, Kiener PA and Wahl AF: Activation of p34cdc2 coincident with taxol-induced apoptosis. Cell Growth Differ 5: 1041-1050, 1994.

8. Schiff PB, Fant J and Horwitz SB: Promotion of microtubule assembly in vitro by taxol. Nature 277: 665-667, 1979.

9. Zhang D, Sun L, Xian W, Liu F, Ling G, Xiao L, Liu Y, Peng Y, Haruna Y and Kanwar YS: Low-dose paclitaxel ameliorates renal fibrosis in rat UUO model by inhibition of TGF-beta/Smad activity. Lab Invest 90: 436-447, 2010.

10. Zhou J, Zhong DW, Wang QW, Miao XY and Xu XD: Paclitaxel ameliorates fibrosis in hepatic stellate cells via inhibition of TGF- $\beta /$ Smad activity. World J Gastroenterol 16: 3330-3334, 2010.

11. Hirose A, Tajima H, Ohta T, Tsukada T, Okamoto K, Nakanuma S, Sakai S, Kinoshita J, Makino I, Furukawa H, et al: Low-dose paclitaxel inhibits the induction of epidermal-mesenchymal transition in the human cholangiocarcinoma CCKS-1 cell line. Oncol Lett 6: 915-920, 2013.

12. Tajima H, Ohta T, Shinbashi H, Hirose A, Tsukada T, Okamoto K, Nakanuma S, Sakai S, Furukawa H, Makino I, et al: Successful treatment of unresectable gallbladder cancer with low-dose paclitaxel as palliative chemotherapy after failure of gemcitabine and oral S-1: A case report. Oncol Lett 4: 1281-1284, 2012.

13. Tajima H, Ohta T, Shinbashi H, Hirose A, Okazaki M, Yamaguchi T, Ohbatake Y, Okamoto K, Nakanuma S, Sakai S, et al: Phase I study of weekly palliative chemotherapy with low-dose third-line paclitaxel for biliary tract cancer. Mol Clin Oncol 6: 753-757, 2017.

14. Eisenhauer EA, Therasse P, Bogaerts J, Schwartz LH, Sargent D, Ford R, Dancey J, Arbuck S, Gwyther S, Mooney M, et al: New response evaluation criteria in solid tumours: Revised RECIST guideline (version 1.1). Eur J Cancer 45: 228-247, 2009.

15. Ueno H, Ioka T, Ikeda M, Ohkawa S, Yanagimoto H, Boku N, Fukutomi A, Sugimori K, Baba H, Yamao K, et al: Randomized phase III study of gemcitabine plus S-1, S-1 alone, or gemcitabine alone in patients with locally advanced and metastatic pancreatic cancer in Japan and Taiwan: GEST study. J Clin Oncol 31: 1640-1648, 2013

16. Uesaka K, Boku N, Fukutomi A, Okamura Y, Konishi M, Matsumoto I, Kaneoka Y, Shimizu Y, Nakamori S, Sakamoto H, et al; JASPAC 01 Study Group: Adjuvant chemotherapy of S-1 versus gemcitabine for resected pancreatic cancer: A phase 3 , open-label, randomised, non-inferiority trial (JASPAC 01). Lancet 388: 248-257, 2016.

17. Okada S, Sakata Y, Matsuno S, Kurihara M, Sasaki Y, Ohashi Y and Taguchi T; Cooperative Group of Docetaxel for Pancreatic Cancer in Japan: Phase II study of docetaxel in patients with metastatic pancreatic cancer: A Japanese cooperative study. Br J Cancer 80: 438-443, 1999.

18. Ryan DP, Kulke MH, Fuchs CS, Grossbard ML, Grossman SR, Morgan JA, Earle CC, Shivdasani R, Kim H, Mayer RJ, et al: A Phase II study of gemcitabine and docetaxel in patients with metastatic pancreatic carcinoma. Cancer 94: 97-103, 2002.

19. Jones DV Jr, Lozano R, Hoque A, Markowitz A, Patt YZ and Phase II: Phase II study of paclitaxel therapy for unresectable biliary tree carcinomas. J Clin Oncol 14: 2306-2310, 1996.

20. Maeda S, Motoi F, Onogawa T, Morikawa T, Shigeru O, Sakata N, Takadate T, Naitoh T, Rikiyama T, Katayose Y, et al: Paclitaxel as second-line chemotherapy in patients with gemcitabinerefractory pancreatic cancer: A retrospective study. Int J Clin Oncol 16: 539-545, 2011.

21. Baek I, Bai CZ, Hwang J, Nam HY, Park JS and Kim DJ: Paclitaxel coating of the luminal surface of hemodialysis grafts with effective suppression of neointimal hyperplasia. J Vasc Surg 55: 806-814.e1, 2012. 
22. Choi HS, Savard CE, Choi JW, Kuver R and Lee SP: Paclitaxel interrupts TGF-beta1 signaling between gallbladder epithelial cells and myofibroblasts. J Surg Res 141: 183-191, 2007.

23. Taghian AG, Abi-Raad R, Assaad SI, Casty A, Ancukiewicz M Yeh E, Molokhia P, Attia K, Sullivan T, Kuter I, et al: Paclitaxel decreases the interstitial fluid pressure and improves oxygenation in breast cancers in patients treated with neoadjuvant chemotherapy: Clinical implications. J Clin Oncol 23: 1951-1961, 2005.

24. Von Hoff DD, Ramanathan RK, Borad MJ, Laheru DA, Smith LS, Wood TE, Korn RL, Desai N, Trieu V, Iglesias JL, et al: Gemcitabine plus nab-paclitaxel is an active regimen in patients with advanced pancreatic cancer: A phase I/II trial. J Clin Oncol 29: 4548-4554, 2011.

25. Alvarez R, Musteanu M, Garcia-Garcia E, Lopez-Casas PP, Megias D, Guerra C, Muñoz M, Quijano Y, Cubillo A, Rodriguez-Pascual J, et al: Stromal disrupting effects of nabpaclitaxel in pancreatic cancer. Br J Cancer 109: 926-933, 2013.

26. Shukuya T, Yasui H, Boku N, Onozawa Y, Fukutomi A Yamazaki K, Taku K, Kojima T and Machida N: Weekly Paclitaxel after failure of gemcitabine in pancreatic cancer patients with malignant ascites: A retrospective study. Jpn J Clin Oncol 40: 1135-1138, 2010.
27. Cereda S and Reni M: Weekly docetaxel as salvage therapy in patients with gemcitabine-refractory metastatic pancreatic cancer. J Chemother 20: 509-512, 2008.

28. Tajima H, Ohta T, Shoji Y, Watanabe T, Makino I, Hayashi H, Nakagawara H, Onishi I, Takamura H, Ninomiya I, et al: Expression of epithelial- mesenchymal transition markers in locally recurrent hepatocellular carcinoma after radio frequency ablation. Exp Ther Med 1: 347-350, 2010.

29. Schrama JG, de Boer MM, Baars JW, Schornagel JH and Rodenhuis S: Palliative chemotherapy after failure of high-dose chemotherapy in breast cancer--toxicity and efficacy. Anticancer Res 23 (3C): 2795-2800, 2003. 